\title{
La planificación ecológica del territorio a través del análisis multitemporal en San Ignacio, Misiones, República Argentina
}

\author{
Sandra Cavallaro y Catalina Fratalocchi
}

\section{Resumen:}

El desarrollo económico y el crecimiento poblacional producen no sólo una demanda constante de territorio sino una creciente presión sobre el medio biofísico. La provincia de Misiones representa en la Argentina uno de los sitos con mayor biodiversidad. Sin embargo, en el sur de esta provincia, en el municipio de San Ignacio, la gran superficie ocupada por emprendimientos agroforestales está provocando la reducción y alarmante fragmentación de la selva, con la consecuente pérdida de biodiversidad. El proceso de deforestaron y siembra de especies comerciales, que si bien señala un incremento positivo en la economía, también presenta indicadores sociales que muestran su escasa relevancia en el mejoramiento de las condiciones de vida de la población Frente a esta situación, el análisis multitemporal a lo largo de los últimos 17 años ha logrado cuantificar la pérdida de ambientes naturales y el crecimiento de las actividades agroforestales. Entendemos que frente a esta realidad, la planificación ecológica del territorio constituye una herramienta que brinda un diagnóstico integral del uso territorial y ofrece los elementos necesarios para definir criterios ambientales en la toma de decisiones. La planificación ecológica se erige como un instrumento de la política ambiental cuyo objeto es regular las actividades productivas, con el fin de lograr un aprovechamiento ambiental racional, promoviendo las estrategias de desarrollo sustentable y evitando la irreversible destrucción de los ecosistemas.

Palabras clave: Planificación ecológica/ estudios multitemporales/ biodiversidad/.

\section{Abstract:}

The economic development and population growth does not only produce a constant demand for territory but also an increasing pressure on the biophysical environment. The province of Misiones in Argentina is one of the sites of greater biological diver- 
sification. Nevertheless on the south of this province, in the town of San Ignacio, a large area occupied by agroforestry enterprises is causing an alarming reduction and fragmentation of the forest, with the consequent loss of biodiversity. Even though the processes of deforestation and sowing of commercial species can provide to a positive economical growth, they also carry social indicators that show their small relevance at improving the inhabitants' life conditions. Taking this situation into account, a multitemporal analysis carried out over the past 17 years has managed to quantify the loss of natural environments and the growth of agroforestry. We understand that, confronting this reality, ecological land planning is a tool that provides a comprehensive assessment of land use providing the necessary elements to define environmental criteria in decision-making. Ecological planning stands as an instrument of environmental policy aimed to the regulation of productive activities in order to achieve a rational environmental use by promoting sustainable development strategies and preventing the irreversible destruction of ecosystems.

Keywords: Ecological Planning / multitemporal studies / biodiversity /.

Sandra Cavallaro y Catalina Fratalocchi (scavall@gmail.com). Servicio Geológico Minero Argentino (SEGEMAR)- CONICET. 


\section{INTRODUCCIÓN}

La provincia de Misiones es una de las regiones con mayor riqueza florística de la República Argentina (Zuloaga et al., 1999, Ponce et al., 2002). Cuenta con 3143 especies de plantas vasculares con numerosos endemismos. La vegetación característica de esta provincia son las selvas subtropicales y las sabanas (Martínez Crovetto, 1963; Cabrera, 1976). En la actualidad, más del 50\% de la vegetación natural fue reemplazada por actividades forestales y agropecuarias, con plantaciones de Pinos, Araucarias, Eucalyptus, yerba mate, té, tabaco y distintos tipos de ganadería (Biganzoli et al; 2004). A pesar de su enorme importancia, los bosques tropicales y subtropicales, tanto a nivel nacional como regional en latinoamerica, sufren una permanente retracción.

Si bien las actividades extractivas en la selva misionera datan desde la época de los Jesuitas, la tasa de deterioro por extracción de especies leñosas de valor comercial o el total reemplazo de los ecosistemas naturales por sistemas de producción forestal, se ha incrementado enormemente en las últimas 5 décadas. Algunas estimaciones informan que entre 1960 y 1985 se talaron 500.000 ha de bosques nativos (Cammarata, E., 1999). Esta situación de deterioro progresivo de los ambientes naturales ha estado íntimamente ligada a legislaciones que involucraban promociones y subsidios a las actividades forestales (Ley Nacional 25080, promulgada en enero de 1999). En el periodo 1998/2002 se registró una disminución de 67.233ha en los bosques nativos de la provincia de Misiones, que ocupaban 1.212.460 ha en el año 2002. En el periodo 2002/2006 se perdieron 62.412 ha más (Cammarata, E., 1999).

Ante este panorama se requieren estudios que permitan no solo cuantificar sino analizar la evolución ambiental regional con el objetivo de una planificación con criterios sustentables. En este contexto, como disciplina de integración, la ecología del paisaje ofrece un marco interpretativo que nos permite analizar tanto la estructura como la dinámica de los distintos mosaicos terrestres en función de los fenómenos sociales y naturales, lo que permite abordar a una planificación ecológica del territorio. Reuniendo las bases metodológicas de la ecología a través del estudio de la dinámica de los ecosistemas y los principios geográficos del paisaje, la ecología del paisaje es capaz de abordar el análisis territorial desde una perspectiva sistémica que integra las actividades económicas con el ambiente natural. 
Asimismo, los mapas de vegetación constituyen un eje fundamental para la planificación territorial. La vegetación suele ser uno de los principales elementos del paisaje, indicador, a su vez, de ciertas condiciones del medio físico.

Podemos decir que la vegetación influye en los procesos morfogenéticos (Ibarra Benlloch, 1989), siendo al mismo tiempo, el elemento esencial para la identificación de los ecosistemas presentes, su estado de conservación y su dinámica. Por otra parte, los mapas de uso del suelo aportan información sobre la distribución de actividades en un área dada y su ubicación en referencia a sitios naturales. Como el uso del suelo constituye un factor dinámico esta cartografía específica nos permite contemplar la realidad actual de un territorio. El análisis de estas variables y la dinámica de los cambios pueden aportar diagnósticos territoriales adecuados a planes de ordenamiento territorial.

En la Dirección de Geología Ambiental y Aplicada del SEGEMAR (Servicio Geológico Minero Argentino) se desarrollan cartas de línea de base con aplicación, entre otros, en estudios de ordenamiento territorial. Uno de estos trabajos, realizado en la Localidad de San Ignacio, Misiones, es el que se utilizó como base para la presente evaluación multitemporal (Tchilinguirián, P., et al, 2005). Es importante destacar que si bien las comunidades vegetales naturales varían con el tiempo estructural y funcionalmente, atravesando diversos estados sucesionales, las interacciones antrópicas suelen modificarlas de un modo más abrupto y definitivo. Estas alteraciones pueden eliminar individuos, poblaciones o ecosistemas completos en función de la implementación de usos comerciales. Estas acciones suelen determinar una fuerte simplificación en la forma y estructura de los parches naturales, eliminando las superficies irregulares a través de recortes lineales que facilitan, por ejemplo, las tareas agroforestales.

\section{DESCRIPCIÓN DEL ÁREA DE ESTUDIO}

El área de estudio está ubicada en el sector occidental de la provincia de Misiones, Argentina, a $60 \mathrm{Km}$ de la Ciudad de Posadas, capital de la provincia. La Localidad de San Ignacio constituye el asentamiento poblacional más importante del área (Mapa 1). 


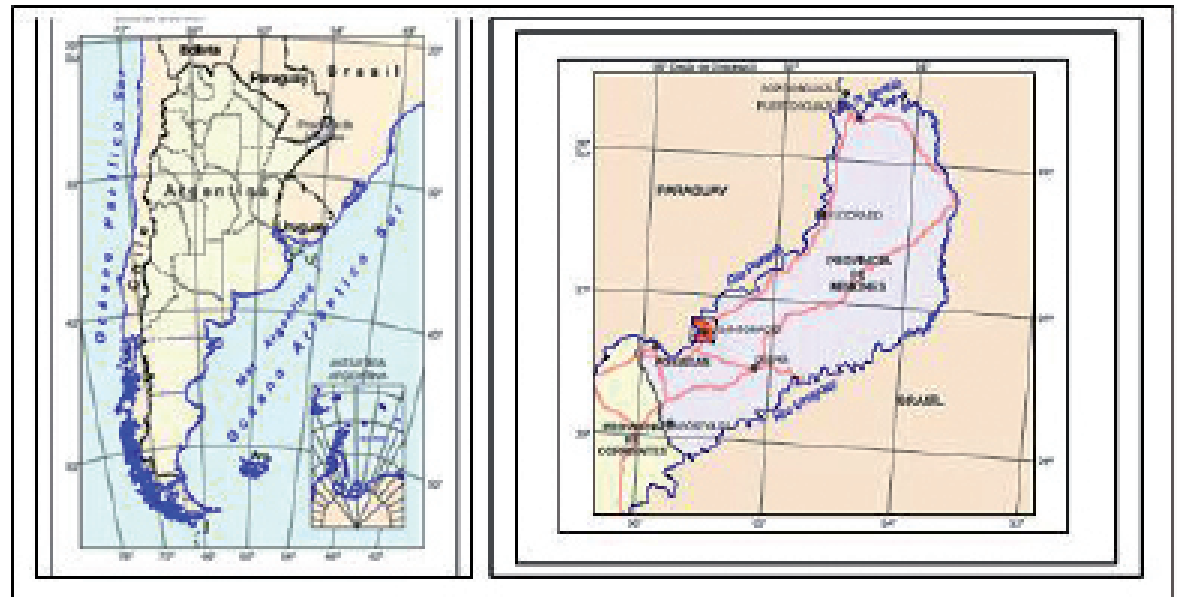

\section{El medio biofísico y social}

La vegetación de la Provincia de Misiones pertenece al dominio amazónico de la región fitogeográfica neotropical (Cabrera, 1976), que abarca un inmenso territorio desde el Sur de Brasil, Paraguay y NE de Argentina, caracterizado en su mayor parte por selvas tropicales y subtropicales. Los condicionamientos hídricos y edáficos determinan la distribución de las comunidades vegetales del área, donde es posible encontrar una gran diversidad de ambientes. Se desarrollan selvas hidrófilas en las riberas del río Paraná, selvas y bosques abiertos con urunday (Astronium balansae) y sabanas con pajonales de "paja azul" y la palmerita enana (Allagoptera campestre). Todas estas unidades se encuentran alteradas con respecto a su estructura original.

El mapa de Unidades Fisonómico Estructurales de vegetación actual confeccionado en el año 2000 fue utilizado como mapa base del presente estudio. El mismo fue simplificado en unidades de síntesis para facilitar la interpretación. (Mapa 1, Tabla 1). 
Figura 2. Mapa 1: A: unidades fisonómico estructurales de

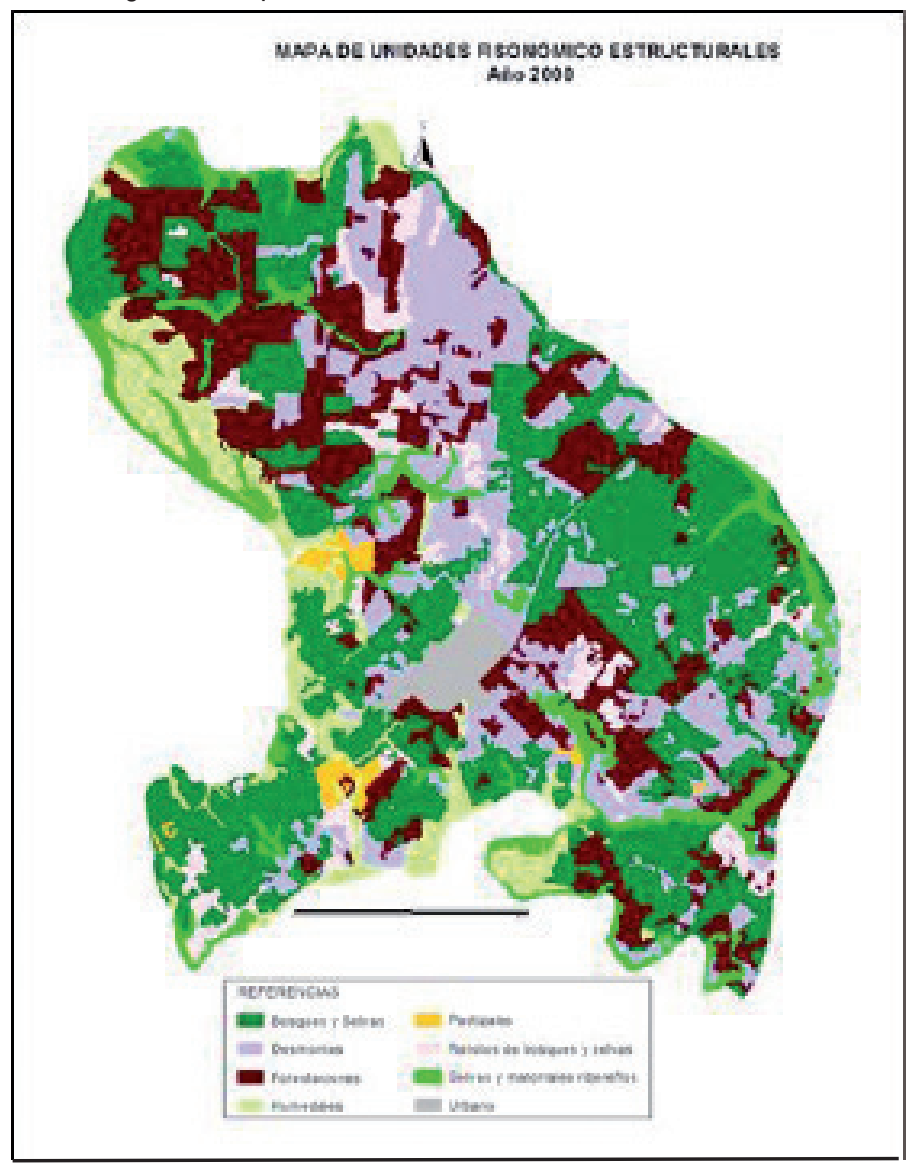


Tabla 1: Descripción de las unidades de síntesis del

mapa de fisonómico estructural de veqetación actual.

\begin{tabular}{|c|c|c|c|}
\hline $\begin{array}{l}\text { Unidades de } \\
\text { sintesis }\end{array}$ & Breve caracterización & $\begin{array}{l}\text { Unidades de } \\
\text { sintesis }\end{array}$ & Breve caracterización \\
\hline $\begin{array}{l}\text { 1. Bosques y } \\
\text { selvas }\end{array}$ & $\begin{array}{l}\text { Bioma multiestratificado, se establece } \\
\text { sobre lomadas suaves. Originalmente } \\
\text { con muy alta biodiversidad, pero con } \\
\text { diferentes grados de deterioro al } \\
\text { momento del muestreo. Por este } \\
\text { motivo se dividió en } 4 \text { subunidades } \\
\text { según su estado de conservación. Se } \\
\text { tomaron como unidades de sintesis las } \\
\text { subunidades I, II y III, considerando } \\
\text { caracteristicas como la cobertura } \\
\text { especifiea y la estratificación. }\end{array}$ & $\begin{array}{l}\text { 2. Selvas y } \\
\text { matorrales } \\
\text { riberefios }\end{array}$ & $\begin{array}{l}\text { Incluye las selvas en galeria y } \\
\text { bosquecillos uni o biestratificados } \\
\text { que ocupan los alhardones del rio } \\
\text { Paraná y arroyos. }\end{array}$ \\
\hline 3. Humedales & $\begin{array}{l}\text { Ocupados por comunidades hidrófilas, } \\
\text { se desarrollan en valles inundables. La } \\
\text { vegetación predominante son los } \\
\text { pajonales oon ciperáoeas, juncáceas y } \\
\text { canaverales. Pueden presentar un } \\
\text { estrato arbustivo en los sectores más } \\
\text { altos. }\end{array}$ & 4. Pastizales & $\begin{array}{l}\text { Corresponde a los pajonales de paja } \\
\text { dura y la palmera enana. Es } \\
\text { caracteristico del área de San } \\
\text { Ignacio, presenta una especie } \\
\text { arbirea, el urunday blanco en } \\
\text { asociaciones formando pequefios } \\
\text { bosquecillos o creciendo en forma } \\
\text { aislada. }\end{array}$ \\
\hline 5. Relictos & $\begin{array}{l}\text { Constituyen espacios relictuales de } \\
\text { bosques y selvas, con coberturas } \\
\text { menores al } 30 \% \text { cuya vegetación } \\
\text { original ha sido evidentemente } \\
\text { alterada. Las cupueras de la unidad } \\
\text { original representan sitios con suclo } \\
\text { desnudo, sin actividad antrópica } \\
\text { actual. }\end{array}$ & 6. Desmontes & $\begin{array}{l}\text { En el mapa original fueron } \\
\text { diferenciados zonas desmontadas } \\
\text { para uso forestal de las zonas } \\
\text { desmontadas pura otros usos } \\
\text { agronómicos. El mapa de sintesis } \\
\text { unifica estos ambientes con objetivos } \\
\text { productivos múltiples. }\end{array}$ \\
\hline 7. Forestaciones & $\begin{array}{l}\text { Son sectores dedicados a cultivos } \\
\text { forestales, generalmente pincs y en } \\
\text { mucha menor proporción a eucaliptos. }\end{array}$ & 8. Urbano & $\begin{array}{l}\text { Representa sectores ocupados por } \\
\text { viviendas, tanto de tipo urhano como } \\
\text { suburbano. }\end{array}$ \\
\hline
\end{tabular}

El patrón del uso del suelo muestra cultivos de Yerba mate, té, mandioca y forestaciones de pinos, dejando espacios selváticos relictuales. En el área se encuentra la reserva natural del Teyú Cuaré y las Ruinas de San Ignacio, zona de patrimonio histórico, además de otros puntos de singular interés desde el punto de vista paisajístico, ecosistémico y cultural.

Dentro de los aspectos demográficos y socioeconómicos más sobresalientes, se puede mencionar que el departamento de San Ignacio posee una superficie de $1.607 \mathrm{Km}^{2}$ y 54.830 habitantes (Censo 2001). Está compuesto por ocho municipios entre los que se encuentra el de San Ignacio, el segundo en importancia en cantidad de habitantes. Esta localidad, que cuenta con 6.263 habitantes, concentra el $60 \%$ de la población urbana del municipio y constituye un centro de atracción de población. La dinámica del crecimiento poblacional de la localidad de San Ignacio no 
se halla vinculada a un incremento en la actividad productiva o comercial sino más bien a una depresión económica en las poblaciones circundantes y en las zonas rurales. Esta situación probablemente trajo como consecuencia la expulsión de población, que se asentó en la localidad de San Ignacio (Tchilinguirián, P. et al, 2005).

\section{OBJETIVOS Y METODOLOGÍA}

Utilizando como base el mapa de unidades fisonómicas de vegetación actual y usos del suelo confeccionado a partir de la Imagen Aster, en el año 2000, se elaboraron los mapas respectivos de los años 1989 y 2006 (con imágenes Landsat). Tomando la definición de vegetación potencial (Rivas-Martinez, 1987) se establecieron, a través de la interpretación de las respectivas imágenes, las fisonomías vegetales presentes en cada momento. El objetivo de este estudio multitemporal fue el de identificar y cuantificar los cambios en la vegetación natural y los ambientes más impactados en este período de tiempo, que representan 17 años. Con el propósito de evaluar multitemporalmente el paisaje y de esta forma intentar analizar los patrones evolutivos específicos en cuanto a la relación usos del suelo/vegetación natural, se utilizaron los índices de uso común en estudios de ecología de paisaje (Mac Garigal \& Marks, 1994; Forman, 1995), que permiten analizar de manera cuali y cuantitativa los cambios producidos. Los índices seleccionados fueron el área total de la clase, el número de parches, la media del tamaño de parche y la densidad de bordes. Es importante destacar que esta selección de años responde principalmente a un criterio vinculado a variables económicas. De hecho, las promociones para las actividades forestales fueron fuertemente impulsadas en los principios de la década del 2000 , con lo cual se intenta correlacionar esta variable con su consecuencia en los ambientes naturales.

Para poder responder a las preguntas básicas ¿qué ambientes fueron modificados? 0 ¿cuáles fueron las transformaciones más frecuentes? y al mismo tiempo cuantificar estos cambios, se procedió al análisis comparado de las tres imágenes a través del módulo Patch análisis del Software ArcGis 9.0. Finalmente se realizó un mapa de conectividad de ambientes naturales implementando un área buffer de $100 \mathrm{~m}$, entre las siguientes unidades: bosque y selvas; humedales; selvas y matorrales ribereños. 


\section{RESULTADOS}

Los cambios en las unidades de vegetación natural se hacen evidentes ya desde la simple visualización de las imágenes satelitales. En un análisis preliminar es posible apreciar una mayor afectación de los ambientes de bosques y selvas, mientras que los sectores de humedales o selvas ribereñas no parecen sufrir grandes modificaciones con respecto al área ocupada.

\section{Determinación de los patrones de cambio de la vegetación entre los años 1989 y 2006.}

Confirmando las observaciones preliminares encontramos que las mayores pérdidas de área se produjeron en la unidad identificada como bosques y selvas, que disminuyeron su superficie de ocupación del $43.75 \%$ en 1989 a $27.74 \%$ en 2006 , lo que representa prácticamente la reducción de $1 / 3$ del área original. Asimismo, como también observáramos anteriormente, los humedales y selvas y matorrales ribereños mantuvieron su porcentaje de ocupación casi sin modificaciones en el período analizado (Tabla 2).

Tabla 2: Indica las áreas correspondientes a las distintas unidades fisonómicas en cada año analizado. La columna \% indica el porcentaje de área ocupada por la unidad fisonómica, en relación al área de estudio

\begin{tabular}{lrrrrrr}
\hline & \multicolumn{2}{c}{ AÑO 1989 } & \multicolumn{2}{c}{ AÑO 2000 } & \multicolumn{2}{c}{ AÑo 2006 } \\
\hline & hu & $\%$ & ha & $\%$ & hu & $\%$ \\
Bosques y selvas & 6627.30 & 43,75 & 5351.66 & 35,33 & 4201.20 & 27,74 \\
Desmontes & 2705.98 & 17,87 & 2973.13 & 19,63 & 4225.31 & 27,90 \\
Forestaciones & 2262.58 & 14,94 & 3315.68 & 21,89 & 2773.81 & 18,31 \\
Selvas y & 1085.57 & 7,17 & 1077.94 & 7,12 & 1077.93 & 7,12 \\
matorrales & & & & & & \\
ribereños & & & & & & \\
Humedales & 1342.79 & 8,87 & 1251.26 & 8,26 & 1248.68 & 8,24 \\
Pastizales & 183.16 & 1,21 & 160.02 & 1,06 & 156.01 & 1,03 \\
Relictos de & 674.80 & 4,46 & 727.12 & 4,80 & 1173.82 & 7,75 \\
bosques y selvas & & & & & & \\
(á. degradadas) & & & & & & \\
\hline Sector urbano & 264.20 & 1,74 & 289.56 & 1,91 & 289.56 & 1,91 \\
\hline
\end{tabular}


Los desmontes y forestaciones fueron ganando superficie, al igual que los relictos de bosques y selvas que corresponden a sectores degradados del bosque original. Pero este análisis no ofrece detalles sobre la dinámica de cambio que se produce en este ambiente, por lo que se realizó un examen de los cambios netos en cada unidad fisonómica y de los intercambios entre éstas, para poder detectar las transiciones más significativas.

\section{Cambios en bosques y selvas}

Esta unidad fisonómica (Mapa 2) pierde 2426.10 ha en el período estudiado. La causa fue, fundamentalmente, las actividades forestales y desmontes, como así también la degradación de la unidad original, que se transforma en relictos.

Figura 3. Mapa 2: Las figuras representan la superficie ocupada por bosques y selvas.

De izquierda a derecha se observan los mapas correspondientes

a los años 1989, 2000 y 2006.

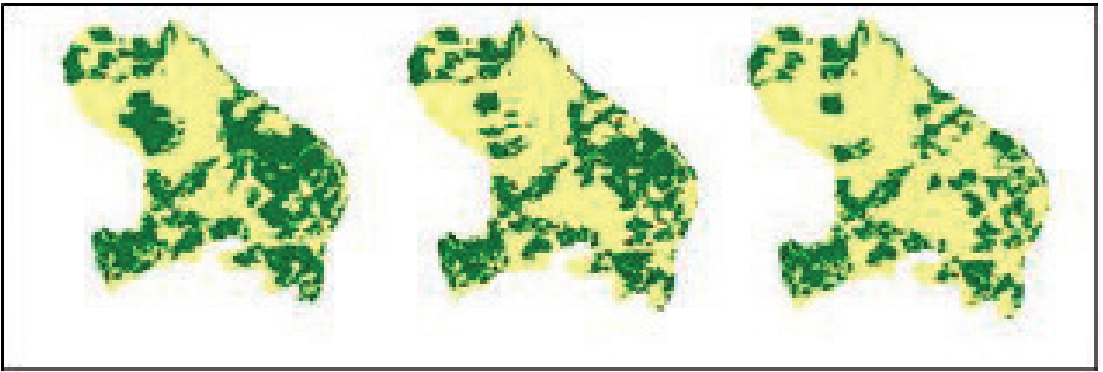

Por otra parte, también se observa una disminución en el número de parches, que pasaron de 158 en el periodo inicial a 79 en el año 2000 y continuaron su reducción hasta llegar a 60 en el año 2006. Al mismo tiempo se puede observar un aumento en el tamaño medio del parche, que pasó de 41.9 ha a 67,7ha entre el año 1989 y 2000, hasta alcanzar las 70ha en el año 2006. Si evaluamos este dato junto con la densidad de bordes, que pasó de 41.56 a 30.57 y 22.74 en el año 2006, podemos asumir que los parches iniciales de bosques y selvas fueron simplificando su mosaico original, al ser eliminados los parches pequeños. Para el año 2006 permanecían los segmentos más grandes, con menor proporción de bordes.

\section{Cambios en selvas y matorrales ribereños}

Esta unidad presentó un bajo porcentaje de cambio en el periodo 1989- 
2006, disminuyendo levemente su superficie total. Aunque de poca extensión, se observan sectores con desmontes y forestaciones que originalmente correspondían a la vegetación ribereña. El número total de parches se redujo de 30 a 24 , al mismo tiempo que se verifica un leve aumento en el tamaño de los mismos (de 36.18 en 1989 a 44.9 en 2006). La densidad de bordes se mantuvo prácticamente constante, lo que indica una simplificación de los mosaicos originales.

\section{Cambios en humedales y pastizales}

Los humedales constituyen otra unidad con pocos cambios significativos. Restringidos a sectores inundables del Río Paraná y arroyos principales, como el Yabebiry, son sitios con muy baja o nula aptitud para los usos productivos o urbanos predominantes en la localidad. Sus fluctuaciones, aunque de poca extensión areal, se encuentran más vinculadas a ciclos de inundación de los cursos de agua que a presiones de uso. La variación en cuanto a la superficie ocupada fue de 94ha, lo que constituye disminución del $7.5 \%$ del área original. Los reemplazos están relacionados con forestaciones y desmontes. También se observa una disminución del número de parches, de 25 en el año 1989 a 21 en 2006, junto con un leve aumento del tamaño medio del parche, de 53.7ha a 59.4ha. La densidad de bordes se mantuvo prácticamente constante, lo que indica que fueron eliminados pequeños sectores, simplificando el mosaico de parches originales.

Con respecto a los pastizales no se manifestaron cambios significativos en el periodo analizado. El área original disminuyó de 183ha en 1989 a 156ha en 2006 , lo que implica una pérdida del $14 \%$ de su superficie. Esta diferencia es equivalente al $1 \%$ del área analizada, razón por la cual no fue mapeada.

\section{Cambios en relictos de bosques y selvas}

El área correspondiente a esta unidad se incrementó en 499.02ha, lo que representa un aumento relativo del 74\% en el periodo 1989-2006. (Mapa 3). 
Figura 4. Mapa 3: Las figuras representan la superficie ocupada por relictos de bosques y selvas. De izquierda a derecha se observan los mapas correspondientes a los años 1989, 2000 y 2006.

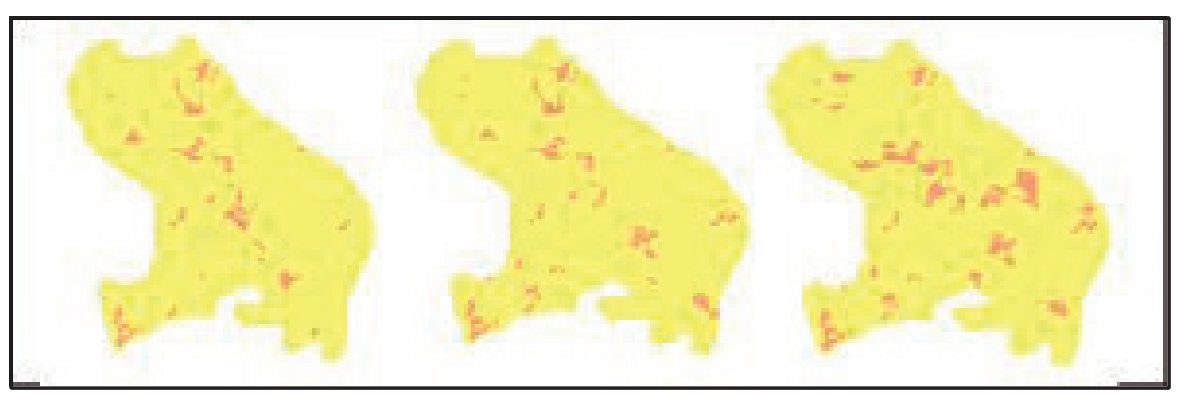

Los cambios producidos en el periodo 1989-2000 son de dos tipos: transformaciones en desmontes y forestaciones, y, por otra parte, esta misma unidad también se nutre de la degradación de bosques y selvas. En todo el periodo el número de parches se incrementa, pasando de 32 en 1989 a 37 y 50 en 2000 y 2006, respectivamente. El tamaño medio del parche fluctúa entre 21.08 y 23.47 ha, mientras que la densidad de bordes se incrementa de 6.5 en 1989 a 9.8 en 2006.

Estos valores están en concordancia con el gran aumento de la superficie de esta unidad.

\section{Forestaciones}

La actividad económica predominante en la localidad de San Ignacio es, sin dudas, la forestación. Las especies principales son Pinus taeda y Pinus elliottii, sin embargo también se siembran Pinus caribaea y Araucaria angustifolia, paraísos (Melia azedarach), kiri (Pawlonia sp.), cedro australiano (Toona ciliata), y eucaliptos (Eucaliptus grandis, E. dunii, E. saligna). La superficie forestada se incrementó un 46.5\% en el periodo 1989-2000 (de 2262.58ha pasó a tener 315.68ha). Luego, el área forestal disminuyó entre el 2000 y el 2006, a 2773.8128ha. Esta reducción implica un reemplazo por desmontes, que estaría en concordancia con la utilización de la madera producida (Mapa 4). 
Figura 5. Mapa 4: Las figuras representan la superficie ocupada por Forestaciones. De izquierda a derecha se observan los mapas correspondientes a los años 1989,2000 y 2006

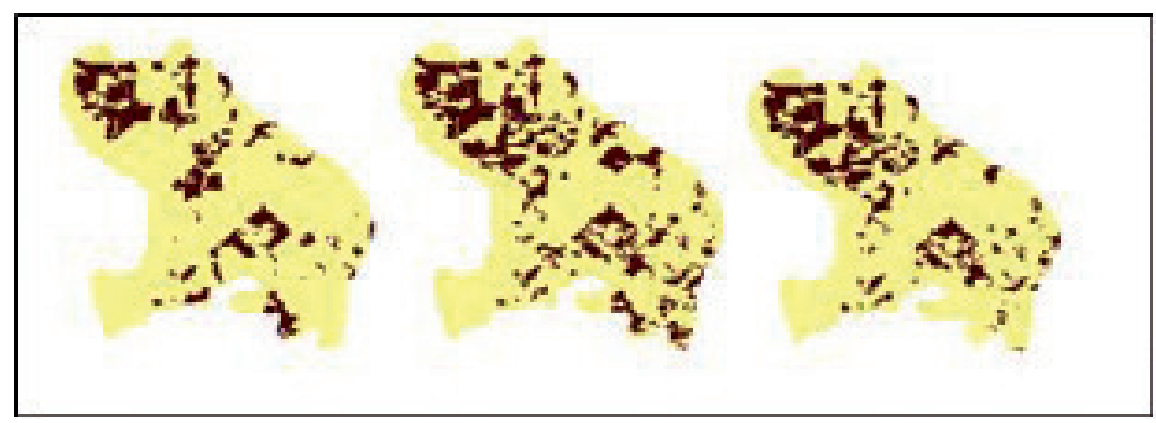

Al igual que la unidad relictos, las forestaciones constituyen ambientes que incrementan su superficie por aporte de otras unidades y al mismo tiempo pierden sectores, tanto por desmontes, como por aportes al sector urbano. El número de parches aumentó de 68 a 136 entre 1989-2000, (casi el 100\%). Desde el año 2000 al 2006 disminuyó a 103. La media del tamaño fluctuó entre 33.27ha, 24.38ha y 26.93 ha en cada año analizado, mientras que la densidad de bordes pasó de 13.9 a 23.23 y 18.7, respectivamente. Estos datos indican que a pesar del aumento en la superficie forestada, el área de los parches fue decreciendo y aumentando su perímetro, lo que indica una mayor atomización de los sectores forestales, esto es, un aumento de la superficie total pero en parcelas más pequeñas que las originales.

\section{Desmontes}

Los desmontes incluyen sectores con diferentes coberturas vegetales que fueron eliminadas, generalmente con el objetivo de su incorporación al uso forestal. En todo el periodo analizado el área de desmontes se incrementó en 1519.33ha (un 35\%) (Mapa 5). Al mismo tiempo, esta unidad cedió parte de su superficie a prácticas forestales. 
Figura 6. Mapa 5: Las figuras representan la superficie ocupada por desmontes. De izquierda a derecha se observan los mapas correspondientes a los años 1989, 2000 y 2006.

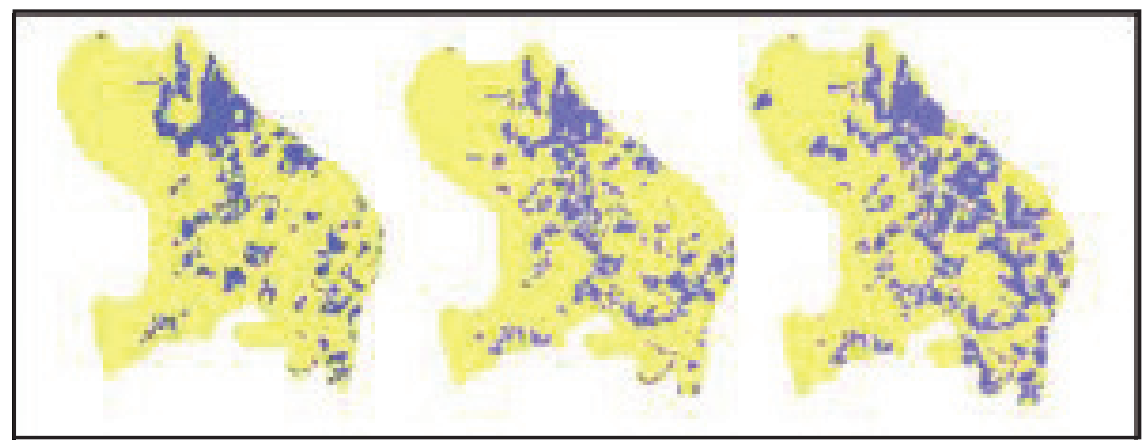

En el periodo 1989-2000 se produce un incremento del sector desmontes de 2705.98 a 2973.13 ha, debido al aporte de bosques y selvas, forestaciones, relictos, selvas y matorrales ribereños. También los desmontes aportaron algo de superficie a forestaciones. El número de parches de esta unidad también se modificó, pasando de 106 en el año 1989 a 115 y 160 en los años 2000 y 2006 respectivamente. A pesar de esto, tanto el tamaño medio del parche como la densidad de bordes no sufrieron importantes modificaciones. El primero varió de 25.53 a 25.85 y 26.41 en cada periodo, mientras que la densidad de bordes pasó de 20.56 a 22.14 y 32.14. Esto indica que las parcelas desmontadas suelen tener áreas relativamente estables, siempre evaluando esta práctica como un antecedente a las actividades forestales.

\section{Fragmentación y Planificación ecológica}

Entendiendo la fragmentación como la pérdida de la continuidad de un ecosistema, podemos inferir que produce importantes cambios en la estructura de las poblaciones y comunidades de plantas y animales, alterando también el funcionamiento del ecosistema. El proceso de fragmentación produce nuevos bordes, con su consecuente efecto de erosión en los ecosistemas. De esta forma, los ambientes fragmentados cambian no sólo en la forma y tamaño de sus parches, sino también en la estructura y composición específica. Remitiéndonos a la situación de San Ignacio en el año 1989 se clasificaron los polígonos de bosques y selvas para verificar su grado de fragmentación al final del periodo analizado. La media del borde de esta unidad se incrementó un $47 \%$, lo que implica el alto nivel de fragmentación producido. Para el año 2006 los sectores de bosques y selvas mejor conservadas 
se encontraban próximos a la Reserva Teyú Cuaré o aledaños a humedales y selvas y matorrales ribereños, esto es, en sitios que por sus condiciones de humedad no resultan óptimos para la siembra de especies forestales comerciales. Entonces, aprovechando esta situación, se realizó un mapa sobre la conectividad de bosques y selvas remanentes, con un área buffer de $100 \mathrm{~m}$, tanto entre sí como con la unidad de humedales y selvas matorrales ribereños (Mapa 6).

Figura 7. Mapa 6: Se destaca en azul la conectividad de ambientes naturales, considerando un buffer de $100 \mathrm{~m}$.

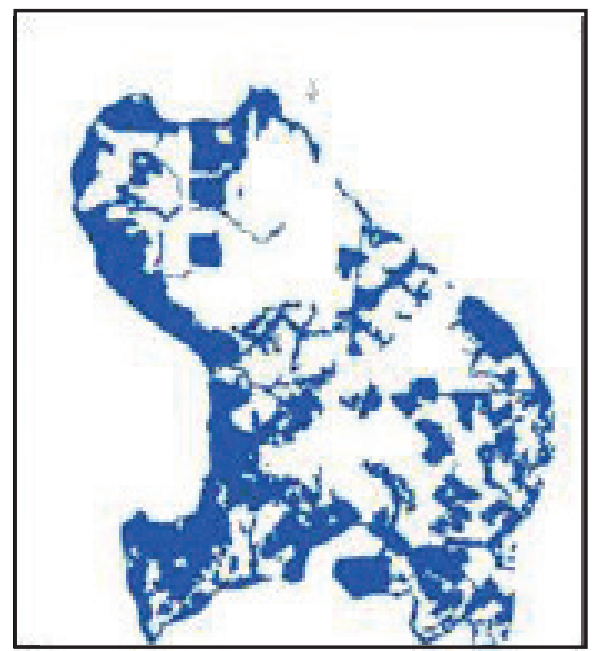

Este mapa puede representar un primer intento para la definición de áreas de interés para la conservación de ambientes naturales. En este sentido, resulta de suma importancia establecer prioridades de conservación mediante la identificación de áreas con características relevantes de biodiversidad, denominadas "hotspot", que no sólo indican sitios con alta biodiversidad sino áreas amenazadas por el avance de las actividades económicas (Myers et al, 2000).

\section{Situación social en la provincia de Misiones}

El Departamento de San Ignacio concentra el $68 \%$ de la superficie forestada de la provincia. Sin embargo, a pesar de la incorporación de importantes superficies de bosques nativos a la actividad económica y productiva, no parece haberse producido una equivalente transformación en la situación social. Esta región, que 
tradicionalmente ha presentado los valores más altos de pobreza e indigencia del país, en el año 2010 presentaba $21.8 \%$ de su población bajo la línea de pobreza y el $5.4 \%$ por debajo de la línea de indigencia. Con respecto del promedio regional, la provincia de Misiones tiene el valor más alto de pobreza extrema, el 7,1\%.

La información del Censo de Población 2010 a nivel departamental no se ha publicado totalmente, por tal motivo solo se han podido seleccionar los indicadores ilustrativos de las condiciones de vida en nuestra área de estudio. Según los datos disponibles, las condiciones de vida en los hogares según el tipo de vivienda casi no se han modificado en el último decenio. Así, el $87,4 \%$ de los habitantes vivía en Casas en 2001 y en 2010 el porcentaje era de 87,6\%. El porcentaje de habitantes que habitaban en Ranchos o Casillas se ha mantenido casi sin alterar. De la misma forma, el tipo de material de los pisos de las viviendas presenta muy leves cambios. Entre ellos se destaca que solo el 53\% los hogares no presenta problemas de terminación, como es la cubierta de los pisos. Respecto de los servicios sanitarios, la proporción de hogares con cloacas ha disminuido levemente y aumentaron los hogares provistos con cámaras sépticas (pozos ciegos) lo que indicaría la persistencia en la deficiencia del servicio. Tomando en cuenta el importante desarrollo que ha tenido la actividad forestal en los últimos años es notorio el escaso impacto que la misma ha tenido en mejorar las condiciones de vida de la población.

\section{DISCUSIÓN Y CONCLUSIONES}

En Argentina se ha estado deforestando a un ritmo calculado entre 280.000 a 300.000 hectáreas por año. La tasa de transformación de bosques nativos, para el cultivo de la soja o para la implantación de árboles de crecimiento rápido para la producción de madera y celulosa, supera hasta en un 300\% el promedio de desmonte mundial1. En nuestro país la permanencia del modelo consumista, incorporado desde las economías más desarrolladas, se presenta no solo en problemas ambientales de difícil resolución sino también en la explotación no sustentable de los recursos naturales. Las fisonomías de bosques y selvas, humedales y matorrales ribereños constituyen los parches del paisaje que sustentan la biodiversidad del

\footnotetext{
${ }^{1}$ La Tasa Anual de Deforestación es un indicador de la magnitud del proceso de deforestación y es el indicador utilizado por la UMSEF (Unidad de Manejo del Sistema de Evaluación Forestal, Secretaría de Ambiente y Desarrollo sustentable.
} 
área de estudio. Al mismo tiempo, la pérdida o modificación de estos ambientes es una consecuencia directa de las actividades antrópicas. La metodología empleada da una idea bastante clara de la dinámica ambiental y puede constituir una base para la planificación ecológica del territorio. Este tipo de ordenamiento promueve mejoras en la calidad de vida de la población ${ }^{2}$ manteniendo la sustentabilidad de los ecosistemas principales.

\section{REFERENCIAS BIBLIOGRÁFICAS}

- Biganzoli, F. y M. E. Múlgura De Romero (2004). Inventario Florístico del Parque Provincial Teyú Cuaré y alrededores (Misiones, Argentina). Darwiniana 42(1-4): 1-24.

- Cabrera, A. L. (1976). Regiones fitogeográficas de la República Argentina, en Enciclopedia Argentina de Agricultura y Jardinería 2(1). ACME, Buenos Aires.

- Cammarata, E. (1999). Misiones en el Territorio de las fronteras paraguayo-brasileñas: sus efectos ambientales. Universidad Nacional de Misiones.

- Cifarelli, D. (2008). El modelo de confieras a Gran Escala. Análisis de sustentabilidad en el alto Paraná Misionero. Fronteras de la Antropología. IX Congreso Argentino de Antropología Social.

- Díaz Langou, G. J. Fernández, y P. Forteza. (2007) Los principales programas de protección social en la provincia de Misiones. www.cippec.org.

- Forman, R. 1995. Land Mosaics. The Ecology of Landscape and Regions. Cambridge University Press. New York, USA.

- Ibarra Benlloch, B., Yetano Ruiz, L. (1989). El estudio de la vegetación en Geografía. Geographicalia. №26. 165-174.

\footnotetext{
${ }^{2}$ No se encuentran dentro del alcance de este estudio situaciones sanitarias especiales de la población, tal como son las provocadas por el uso de agroquímicos (desmalezantes, defoliantes, etc.) sumamente peligrosos para la salud humana
} 
- Morello, J. y A. Rodriguez. (2007). Ambiente y Economía en un país joven agroexportador: Argentina. Fronteras 6, Facultad de Arquitectura, diseño y urbanismo. Universidad de Buenos Aires. Año 6 Número 4.

- Ponce, M. M. , Mehltreter, K. \& De La Sota, E. R. (2002). Análisis biogeográfico de la diversidad pteridofítica en Argentina y Chile continental. Revista Chilena Hist. Nat. 75: 703-717.

- Martínez Crovetto, R. (1963). Esquema fitogeográfico de la Provincia de Misiones (República Argentina). Bonplandia 1: 171-223.

- Mcgarigal, K. \& B. Marks. 1994. FRAGSTATS: spatial pattern analysis program for quantifying landscape structure. USDA for Serv. Gen. Tech. Rep. PNW- 351. $67 p p$.

- Myers N, Mittermeier RA, Mittermeier CG, daFonseca GAB, Kent J. 2000. Biodiversity hotspots for conservation priorities. Nature 403: 853-858

- Myers N, Mittermeier RA, Mittermeier CG, daFonseca GAB, Kent J. 2000. Biodiversity hotspots for conservation priorities. Nature 403: 853-858

- Rivas-Martínez, S. (1987) Memoria del mapa de series de vegetación de España. 269p. Icona, Serie Técnica. Servicio de Publicaciones del Ministerio de Agricultura, Pesca y Alimentación. Madrid.

- 2005. "Estudio Geocientífico aplicado al Ordenamiento Territorial". San Ignacio, Provincia de Misiones. Tchilinguirián, P., Cavallaro S, Ducos S., Fratalocchi C., Marengo H., Palma Y., Tejedo A., Toloczyki M., Portaneri J. Convenio de Cooperación Técnica Geológica Argentino Alemán. SEGEMAR - BGR (Servicio Geológico Minero Argentino - Bundesantalt Fur Geowissenchaften und Rohstoffe). Buenos Aires, Anales N 43. ISSN 0328-2325.

- Zuloaga, F.O. \& O. Morrone (Eds.). (1999). Catálogo de las plantas vasculares de la República Argentina. II. Angiospermae (Dicotyledoneae). Monogr. Syst. Bot. Missouri Bot. Gard. 74: 1-1269. http://extension.facfor.unam.edu.ar/sifip/ inventario.htm. Consultado Abril 2010. 
- Informe económico: Provincia de Misiones - Observatorio de Comercio y Servicios - Cámara Argentina de Comercio - Año 2011

- Primer Inventario Nacional de Bosques Nativos. Proyecto Bosques Nativos y Áreas Protegidas. BIRF 4085-AR. 1998-2005. República Argentina. Secretaría de Ambiente y Desarrollo Sustentable de la Nación 